\title{
Outcomes into Adulthood of Survivors Born Either Extremely Low Birthweight or Extremely Preterm
}

\section{Lex W Doyle}

Research Office, Royal Women's Hospital, Departments of Obstetrics and Gynaecology, Paediatrics, University of Melbourne, Victorian Infant Brain Studies, Murdoch Children's Research Institute, Melbourne, Australia

\section{ABSTRACT}

We need to understand the outcomes into adulthood for survivors born either extremely low birthweight (ELBW; <1,000 g) or extremely preterm (EP; <28 weeks' gestational age), particularly their blood pressure and cardiovascular metabolic status,respiratory function, growth, psychological and mental health performance, and functional outcomes. Blood pressure is higher in late adolescence and early adulthood in ELBW/EP survivors compared with controls. In some studies, expreterm survivors have higher insulin and blood lipid concentrations than controls, which may also increase their risk for later cardiovascular disease. ELBW/EP survivors have more expiratory airflow obstruction than do controls. Those who had bronchopulmonary dysplasia (BPD) in the newborn period have even worse lung function than those who did not have BPD. As a group, they are unlikely to achieve their full lung growth potential, which means that more of them are likely to develop chronic obstructive airway disease in later life. Although they are smaller than term born controls, their weight gradually rises and ultimately reaches a mean $z$-score close to zero in late adolescence, and they ultimately attain a height $z$ score close to their mid-parental height $z$-score. On average, ex-preterm survivors have intelligence quotient (IQ) scores and performance on tests of academic achievement approximately 2/3 SD lower than do controls, and they also perform less well on tests of attention and executive function. They have similar high rates of anxiety and depression symptoms in late adolescence as do controls. They are, however, over-represented in population registries for rarer disorders such as schizophrenia and Autism Spectrum Disorder. In cohort studies, ex-preterm survivors mostly report good quality of life and participation in daily activities, and they report good levels of self-esteem. In population studies, they require higher levels of economic assistance, such as disability pensions, they do not achieve education levels as high as controls, fewer are married, and their rates of reproduction are lower, at least in early adulthood. Survivors born ELBW/EP will present more and more to health carers in adulthood, as they survive in larger numbers.

Key Words: Extremely preterm, Extremely low birthweight, Adult, Outcomes
Received: 2 January 2018

Revised: 21 January 2018

Accepted: 24 January 2018

Correspondence to: Lex W Doyle

Department of Obstetrics and Gynaecology, The Royal Women's Hospital, 20 Flemington Rd, Parkville Victoria 3052, Melbourne, Australia

Tel: +6-13-8345-3716

Fax: +6-13-83453702

E-mail: lwd@unimelb.edu.au

Copyright(c)

By Korean Society of Neonatology.

All right reserved.

This is an Open-Access article distributed under the terms of the Creative Commons Attribution Non-Commercial License (http://creativecommons.org/licenses/ by-nc/4.0), which permits unrestricted non-commercial use, distribution, and reproduction in any medium, provided the original work is properly cited. 


\section{INTRODUCTION}

As more infants born either extremely low birthweight (ELBW; $<1,000$ g) or extremely preterm (EP; <28 weeks' gestational age) survive into adulthood with advances in perinatal and neonatal care, they will present increasingly to health carer providers in adulthood over the coming years. In addition to the health issues common to all adults, it is important to understand if there are any health problems unique to being born very tiny or too early. The aim of this article is to review the evidence that has accumulated concerning the health and functional outcomes into adulthood of survivors born either ELBW or EP. The areas covered will include blood pressure and metabolic disorders related to cardiovascular disease, respiratory function, particularly expiratory airflows, growth, psychological performance, academic achievement, mental health, and functional outcomes.

\section{METHODOLOGICAL ISSUES}

To determine rates of outcomes requires knowledge of the number with the outcome divided by the number at risk. Ideally the number at risk would be derived from entire populations of infants born within geographical regions over finite periods of time. Next best would be complete cohorts derived from single hospitals, or networks of hospitals, which report outcomes on all infants cared for within their institutions over discrete periods of time.

To understand if rates of outcomes are more prevalent in survivors born ELBW/EP, it is important to have controls born of normal birthweight $(\geq 2,500$ g) or at term ( $\geq 37$ completed weeks' gestational age) who are assessed simultaneously with preterm cohorts, with assessors blinded to knowledge of the group to which individuals belong.

Another important issue is the follow-up rate; the higher the better. Unfortunately, those not followed have higher rates of adverse outcomes compared with those who are followed, and hence low follow-up rates will result in underestimations of adverse outcomes, particularly for psychological disorders ${ }^{1)}$.

In recent years there have been many reports on whole populations where data from the perinatal period have been linked to data on rates of health problems in later life; many such reports come from Scandinavian countries. Large sample sizes are possible and hence rates of outcomes can be determined with considerable precision. Moreover, rare outcomes can be compared between groups of interest. A relative drawback of population linkage studies is that the outcomes are determined by those reported to health care systems, which exist primarily for financial reasons rather than for accuracy or completeness of all diagnoses relevant to an individual. Moreover, the data relate mostly to diagnoses for hospital admissions, or to prescription of medications; not all health problems require hospital admission or drug prescriptions. Clearly, not all relevant outcomes of interest are captured by routine health care systems. Consequently, cohort studies, where participants are assessed in detail to answer specific questions, are also required, to complement data from population linkage studies.

This review will synthesise data from multiple sources, but will focus on well-designed cohort studies, both from geographicallydefined regions or from single hospitals, as well as populationlinkage studies. Of the cohort studies, data from 297 consecutive survivors born ELBW/EP in the state of Victoria in 1991-92 and 262 term-born controls matched for sex and sociodemographic variables and who were assessed at 18 years of age will recur in different sections. This latter cohort of ELBW/EP survivors and controls, known as the The Victorian Infant Collaborative Study (VICS) 1991-92 cohort, has been extensively studied, covering most of the areas in this review.

\section{CARDIOVASCULAR OUTCOMES}

Cardiovascular disease is responsible for approximately onethird of all deaths in the developed world ${ }^{2}$. High blood pressure is a particular risk variable for cardiovascular disease and is important when considering primary prevention of cardiovascular disease. On a population level, every $2 \mathrm{mmHg}$ decrease in diastolic blood pressure is associated with a $17 \%$ decrease in the prevalence of hypertension, a $6 \%$ reduction in coronary artery disease and a $15 \%$ reduction in stroke or transient ischemic attacks ${ }^{3)}$.

In a recent individual participant data meta-analysis of nine cohort studies from Europe, North America, and Australia, 1571 very low birthweight (VLBW; <1500 g) survivors were compared with 777 controls $^{4}$. The cohorts were born between the late 1970 s and the early 1990s, and had their blood pressures measured clinically at ages ranging from $16-24$ years. Systolic blood pressure was higher in the VLBW groups compared with the controls by a mean of $3.4 \mathrm{mmHg}$, with a $95 \%$ confidence interval (CI) 2.2 to 4.6 
mmHg. Diastolic blood pressure was higher in VLBW survivors by a mean of $2.1 \mathrm{mmHg}$ (95\% CI 1.3 to 3.0). The differences between VLBW and control groups were larger in females than in males.

Ambulatory blood pressure is also higher in ex-preterm survivors. From the VICS 1991-92 cohort, 179 ELBW/EP 18-yearolds and 125 contemporaneous controls had ambulatory blood pressure measured for 24 hours ${ }^{5)}$. Recordings were taken $1 / 2$ hourly when awake, and hourly when asleep. The preterm group had significantly higher mean systolic blood pressures over 24 hours (mean difference $3.2 \mathrm{mmHg}$, 95\% CI 0.1, 6.4), and when awake (mean difference $3.9 \mathrm{mmHg}$, 95\% CI 0.7, 7.2). Mean blood pressure and diastolic blood pressures were also higher in the preterm group compared with controls. Importantly, blood pressure tracked over time within individuals; systolic blood pressure at age 8 years was positively associated with systolic blood pressure at age 18 years, which means that some individuals destined for higher blood pressure in adulthood may be able to be identified earlier in childhood.

In whole populations, being born EP is associated with higher rates of being treated for hypertension; in a study of 636,552 live births born in 1973-79 in Sweden the odds ratio for any antihypertensive medication at ages 25 -37 years was 2.5 (95\% CI 1.1, 5.7) for those born at 23-27 weeks' gestation compared with those born at 37-42 weeks ${ }^{6)}$. In that study there was a gradual reduction in the odds of receiving antihypertensive medication as gestational age increased towards term.

Apart from blood pressure, cardiometabolic profiles are also of interest as high blood glucose and serum lipids are associated with increased risks for cardiovascular disease. In a cohort study from Finland of VLBW infants discharged from Children's Hospital at Helsinki University Central Hospital born 1978-1985, $50 \%(166 / 335)$ were assessed at $18-27$ years of age ${ }^{7}$. A 75 g glucose tolerance test was given to 163 VLBW participants and results compared with 169 controls born at term. There was a 7\% increase in the 2 -hour glucose concentration, a $17 \%$ increase in fasting insulin, a 40\% increase in 2-hour insulin, and a 19\% higher insulin resistance index determined by homeostasis model assessment (HOMA-IR). Serum lipid concentrations were similar between the groups.

From the Northern Finland Birth Cohort of infants born in 1986 there were 6642 participants assessed at 16 years of age, $79(1.2 \%)$ of whom who had been born $<34$ weeks' gestation ${ }^{8)}$. Compared with those born at term, girls born preterm had higher blood pressure but no difference in serum lipids compared with control girls. In contrast, in boys born preterm compared with controls there was little difference in blood pressure but higher cholesterol by $7 \%$, and $12 \%$ higher low-density lipoprotein cholesterol and apolipoprotein B concentrations.

\section{EXPIRATORY AIRFLOWS}

Airway growth peaks in the early to mid-20s, after which it gradually declines with age ${ }^{9)}$. Fortunately most people will never develop symptomatic lung disease from the natural decline in lung function with age. However, it appears that airway growth is suboptimal in those born ELBW/EP compared with controls, not only in childhood but also in adulthood; hence more ELBW/EP survivors may develop chronic obstructive pulmonary disease as they age than would otherwise be expected.

Expiratory airflows were measured at 18 years of age in $70 \%$ of the ELBW/EP group and 59\% of controls in the VICS 1991-92 $\operatorname{cohort}^{10)}$. Values were adjusted for age, height, sex and ethnicity and $z$-scores produced relative to the reference values of the Global Lung Initiative ${ }^{11)}$. The variables measured included the forced expired volume in one second $\left(\mathrm{FEV}_{1}\right)$, the forced vital capacity (FVC), the ratio of the two ( $\left.\mathrm{FEV}_{1} / \mathrm{FVC}\right)$, and the flow between $25 \%$ and $75 \%$ of the vital capacity $\left(\mathrm{FEF}_{25-75 \%}\right)$. The ELBW/EP group had substantially reduced airflows for all variables relative to the controls, who had $z$-scores close to the expected values of zero (Table 1). The reductions were substantial. at approximately -1 SD for both the FEV1 and the $\mathrm{FEF}_{25-75 \% \text {. }}$

ELBW/EP adolescents who had BPD in the newborn period have substantially reduced airflow compared ELBW/EP adoles-

Table 1. Z-Scores for Expiratory Flows at 18 Years Contrasted Between Extremely Low Birth Weight (ELBW) or Extremely Preterm (EP) and Control Groups Born in Victoria in 1991-92

\begin{tabular}{lccc} 
Variable & $\begin{array}{c}\text { ELBW/EP } \\
\mathrm{n}=209\end{array}$ & $\begin{array}{c}\text { Controls } \\
\mathrm{n}=154\end{array}$ & $\begin{array}{c}\text { Mean difference } \\
(95 \% \mathrm{CI})\end{array}$ \\
\hline $\mathrm{FEV}_{1}$ & $-1.03(1.08)^{*}$ & $-0.10(1.03)^{*}$ & $-0.92(-1.14,-0.71) P<0.001$ \\
FVC & $-0.48(1.03)$ & $-0.09(0.87)$ & $-0.38(-0.58,-0.18) P<0.001$ \\
FEV $_{1} / \mathrm{FVC}$ & $-0.85(1.25)^{*}$ & $-0.06(0.97)^{*}$ & $-0.80(-1.03,-0.56) P<0.001$ \\
FEF $_{25-75 \%}$ & $-1.37(1.19)$ & $-0.23(0.98)$ & $-1.14(-1.37,-0.90) P<0.001$ \\
\hline
\end{tabular}

${ }^{*} \mathrm{n}=1$ missing data.

Data are mean (SD), unless otherwise stated.

Abbreviations: ELBW, extremely low birth weight; EP, extremely preterm; $\mathrm{CI}$, confidence interval; $\mathrm{FEV}_{1}$, forced expiratory volume in $1 \mathrm{~s}$; FVC, forced vital capacity; $\mathrm{FEF}_{25-75 \%}$, forced expiratory flow at $25-75 \%$ of FVC. 
cents who did not have BPD. In the VICS 1991-92 cohort, at 18 years of age ELBW/EP adolescents with BPD had reductions in $\mathrm{FEV}_{1}$ and $\mathrm{FEF}_{25-75 \%}$ approximately 2/3 SD lower than those who did not have BPD.

In addition to the data from the VICS 1991-92 cohort, expiratory flows have been reported from several other cohorts in late adolescence or early adulthood, including from single hospital studies of predominantly VLBW births in 1964-73 from San Francisco ${ }^{12)}$, 1977-1982 from Melbourne ${ }^{13,14)}$, 1978-1985 from Helsinki ${ }^{15)}$, 19781993 from Belfast ${ }^{16)}$, 1979-80 from London ${ }^{17)}$, and 1986-88 from Trondheim $^{18)}$, as well as geographically defined studies from births in 1982-85 and 1991-92 in Bergen ${ }^{19,20)}$, and 1983 from the Netherlands ${ }^{21)}$. Not all studies have reported $z$-scores for their expiratory flow data, but it is still possible to calculate standardised mean differences (SMD) and 95\% CIs as long as the mean, SD and sample size for each group have been reported. Comparing preterm cohorts with controls, for the hospital cohorts the SMD for $\mathrm{FEV}_{1}$ was $-0.71,95 \% \mathrm{CI}-1.04,-0.38$, and for regional cohorts it was $-0.90,95 \%$ CI $-1.12,-0.67$ without the VICS 1991-92 cohort data, and $-0.89,95 \%$ CI $-1.04,-0.73$ with the VICS 1991-92 cohort data. The data are mostly consistent across these different studies and clearly indicate that survivors born ELBW/EP are unlikely to achieve their full airway growth potential.

\section{GROWTH}

Infants born ELBW/EP are very fragile at birth and have considerable difficulties tolerating enteral feeds, so much so that parents often wonder if their baby will ever grow. As survival becomes increasingly likely, some parents begin to ask about the ultimate size of their baby as an adult.

In a systematic review of four studies reporting body size in late adolescence or early adulthood of participants who had been born either $<32$ weeks or $<1,500 \mathrm{~g}$, Euser et al reported that mean height $z$-scores were less than zero, ranging from -1.02 to -0.26 , whereas mean weight $\mathrm{z}$-scores were closer to zero, ranging from -0.48 to $0.26^{22)}$.

In a subsequent study of adults who had weighed $<1,001 \mathrm{~g}$ at birth from a geographical region in Canada, Saigal et al reported that ELBW participants had substantially lower weight $z$-scores than expected through early childhood but then some catch-up in adolescence; however, as adults at a mean age of 23 years they remained substantially lighter than controls born at term ${ }^{23)}$. Their mean height $z$-scores were also below the expected value of zero throughout childhood and into adulthood, with no sign of any catch-up growth.

From theVICS 1991-92 cohort born EP and controls, Roberts et al. $^{24)}$ described body size at birth, 2, 5, 8 and 18 years of age, corrected for prematurity. Weight $z$-scores were lower at all ages in the EP group compared with controls (Table 2). Although the gap between the two groups increased in early childhood, it narrowed through later childhood but remained substantial in late adolescence, with a mean difference between the groups of -0.49 (95\% CI -0.76, -0.21) at 18 years. The difference in height $z$-scores between the groups remained relatively constant between 2 and 18 years, and the mean difference at 18 years was $-0.84(95 \%$ CI -1.06, -0.62) (Table 2). Interestingly, the mean height $z$-score at 18 years of the preterm group was -0.59 , quite close to their mean mid-parental height $z$-score of -0.35 , which means that the best estimate of the height in adulthood of an infant born EP is obtained by considering the heights of the infant's parents. Because the gap in weight $z$-scores is narrower than the gap in height $z$-scores between the EP and control groups, the difference

Table 2. Body Size Z-Scores at Different Ages Contrasted Between Extremely Preterm (EP) and Term-Born Controls Born in Victoria in 1991-92

\begin{tabular}{lccc}
\hline Ages & $\begin{array}{c}\mathrm{EP} \\
\mathrm{n}=225\end{array}$ & $\begin{array}{c}\text { Controls } \\
\mathrm{n}=262\end{array}$ & $\begin{array}{c}\text { Mean difference } \\
(95 \% \mathrm{CI})\end{array}$ \\
\hline Weight & & & \\
Birth & $-0.27(0.87)$ & $-0.06(0.89)$ & $-0.22(-0.38,-0.06)$ \\
Discharge & $-1.65(1.00)$ & $-0.49(0.82)$ & $-1.16(-1.33,-0.99)$ \\
2 years & $-0.75(1.47)$ & $0.22(1.05)$ & $-0.97(-1.21,-0.73)$ \\
5 years & $-0.56(1.53)$ & $0.30(1.16)$ & $-0.86(-1.12,-0.60)$ \\
8 years & $-0.30(1.48)$ & $0.38(1.11)$ & $-0.67(-0.93,-0.42)$ \\
18 years & $0.07(1.52)$ & $0.45(1.09)$ & $-0.38(-0.67,-0.09)$ \\
Height & & & \\
2 years & $-0.44(1.19)$ & $0.35(0.97)$ & $-0.79(-1.00,-0.59)$ \\
5 years & $-0.29(1.23)$ & $0.29(0.91)$ & $-0.59(-0.79,-0.38)$ \\
8 years & $-0.29(1.25)$ & $0.24(1.18)$ & $-0.52(-0.76,-0.29)$ \\
18 years & $-0.47(1.14)$ & $0.26(0.98)$ & $-0.73(-0.97,-0.50)$ \\
Mid-parental & -0.35 & -0.15 & $-0.21(-0.39,-0.03)$ \\
BMI & & & \\
2 years & $-0.81(1.22)$ & $-0.10(1.07)$ & $-0.70(-0.90,-0.50)$ \\
5 years & $-0.62(1.44)$ & $0.16(1.15)$ & $-0.78(-1.03,-0.53)$ \\
8 years & $-0.06(1.41)$ & $0.37(1.16)$ & $-0.42(-0.67,-0.18)$ \\
18 years & $0.40(1.42)$ & $0.42(1.08)$ & $-0.03(-0.31,0.25)$ \\
\hline Data are & & & \\
\hline
\end{tabular}

Data are mean (SD), unless otherwise stated.

Abbreviations: CI, confidence interval; BMI, body mass index. 
in BMI $z$-scores gradually narrowed through childhood and was negligible by 18 years of age (Table 2). However, both groups had mean $z$-scores for BMI above zero at 18 years, meaning that both groups are contributing equally to the obesity epidemic.

Along the same lines as the reports mentioned above, Darlow et al. ${ }^{25)}$ studied a cohort of consecutive survivors who had been born VLBW in 1986 in New Zealand and found that they were on average $4.2 \mathrm{~cm}$ shorter and $5.6 \mathrm{~kg}$ lighter than term controls at a mean age of 22 years.

\section{PSYCHOLOGICAL OUTCOMES}

Children born preterm have deficits in cognitive functioning in early childhood compared with controls; typically they have intelligence quotient (IQ) scores approximately $2 / 3$ SD lower than controls ${ }^{26)}$. There are fewer studies of IQ in late adolescence or early adulthood. From the VICS 1991-92 cohort $^{27)}$, IQ was measured at 18 years of age with the Wechsler Abbreviated Scale of Intelligence, and educational achievement in reading, spelling, and math computation were assessed with the Wide Range Achievement Test (WRAT4); each test has a mean of 100 (SD 15). Although mean scores for the EP cohort were close to the expected mean of 100 for all tests except math computation, the EP group were substantially lower than the term controls (Table 3 ). The difference in IQ was approximately $2 / 3 \mathrm{SD}$, even after adjustment for sociodemographic variables (sex, social class and maternal education). The largest difference between groups on academic achievement was for math computation. In the VICS 1991-92 study most participants also had brain Magnetic Resonance Imaging (MRI) scans at 18 years of age. Brain volumes were smaller in EP adolescents compared with controls; e.g., for total brain tissue volume the mean difference was $-5.9 \%$ (95\% CI
$-8.0,-3.7 \%)$. Volumes of total brain tissue and some other brain tissues and structures correlated positively with IQ and academic achievement. Total brain tissue volume explained between 20$40 \%$ of the differences between EP and control groups in IQ and academic achievement scores.

Hack et al reported results from 242 VLBW survivors and 233 controls born in 1977-1979 in Cleveland, USA, and assessed at 20 years of age; they found that the VLBW cohort had lower IQ scores by 5 points overall, and lower scores on tests of academic achievement ${ }^{28)}$, consistent with the results from the VICS 1991-92 cohort at 18 years of age.

On a whole population basis, intellectual impairment increases with diminishing gestational age at birth. In a study from Norway of 317,761 male conscripts born in 1967-1979, Eide et al. reported that the odds for low IQ were 1.93 (95\% CI 1.55, 2.41) for those born at 26-29 weeks' gestation compared with those born at 39-41 weeks ${ }^{29)}$.

In the VICS 1991-92 cohort, survivors born EP were disadvantaged in other cognitive areas compared with controls in late adolescence, including in executive function, where they had more problems with verbal processing speed, attentional control, cognitive flexibility, and goal-setting (effect sizes, -0.7 to $-0.2 \mathrm{SD})^{30}$. They also performed worse on tests of selective and executive attention, had greater rates of clinically important attention problems with odds ratios ranging from 2.5 to 3.3 , and also had more behavioural attention problems reported by their parents ${ }^{31)}$.

\section{MENTAL HEALTH}

The mental health of survivors born ELBW/EP has not been commonly reported in late adolescence or early adulthood. In a review of psychiatric symptomatology in preterm survivors

Table 3. IQ and Academic Performance at 18 Years of Age Contrasted Between Extremely Preterm (EP) and Control Groups Born in Victoria in 1991-92

\begin{tabular}{lccc}
\hline Assessments & $\begin{array}{c}\mathrm{EP} \\
\mathrm{n}=147\end{array}$ & $\begin{array}{c}\text { Controls } \\
\mathrm{n}=131\end{array}$ & $\begin{array}{c}\text { Mean difference } \\
(95 \% \mathrm{CI})\end{array}$ \\
\hline IQ & $95.7(15.9)$ & $107.6(12.8)$ & $-11.9(-15.4,-8.5)$ \\
Reading & $95.5(13.5)$ & $101.1(13.6)$ & $-5.6(-8.8,-2.4)$ \\
Spelling & $97.1(15.2)$ & $105.1(14.0)$ & $-8.0(-11.5,-4.6)$ \\
Math computation & $85.2(14.0)$ & $95.6(14.3)$ & $-10.3(-13.7,-6.9)$ \\
\hline
\end{tabular}

*adjusted for sex, social class and maternal education.

Data are mean (SD), unless otherwise stated.

Abbreviations: IQ, intelligence quotient; EP, extremely preterm; CI,confidence interval. 
compared with term-born peers at ages from 10 to 25 years, any psychiatric diagnosis was increased in preterm groups with an OR of 3.7 (95\% CI 2.6-5.2), as were rates of any anxiety or depressive disorders (OR 2.9, 95\% CI 1.7-4.7) ${ }^{32)}$.

In the 1991-92 VICS cohort, 72\% (215/297) of ELBW/EP survivors and $60 \%$ (157/262) of controls had psychiatric interviews at 18 years of age, including the Structured Clinical Interview for DSM-IV Disorders Axis1 Non-Patient version [SCID-1 NP], and the Children's Interview for Psychiatric Syndromes [ChIPS]-ADHD module, for mood, anxiety, attention deficit hyperactivity disorder (ADHD), psychosis, and other mental health disorders ${ }^{33)}$. Rates of any SCID-1 NP disorder were similar (ELBW/EP 23\%; control $21 \%$ ), including rates of any mood (ELBW/EP 16\%; control 15\%) or anxiety disorder (ELBW/EP 11\%; control 10\%), although ADHD was twice as common (ELBW/EP 15\%; control 7\%; OR 2.2, 95\% CI 1.1, 4.6). Psychotic disorders were uncommon in both groups (ELBW/EP 0\%; control 1\%).

Similar results were reported by Darlow et al who interviewed 230 VLBW young adults ( $71 \%$ of survivors) born in New Zealand in 1986 and 69 controls at age 22 to 23 years ${ }^{25)}$. In the previous 12 months rates of depression (20.8\% VLBW vs. $18.8 \%$ controls), anxiety (19.1\% VLBW vs. $18.8 \%$ controls) and suicide ideation/ attempts (8.7\% VLBW vs. 8.7\% controls) were similar between VLBW and control groups.

Mental health problems have, however, been reported to occur more commonly in ex-preterm survivors compared with controls by other groups of researchers. In a study of ELBW survivors from Canada, Saigal et al reported that $14.1 \%$ of those born weighing $<1,001 \mathrm{~g}$ in 1977-1982 compared with $6.0 \%$ of controls had depression at a mean age of 23 years ${ }^{34)}$. In a later report when the same cohorts had a mean age of 32 years, $32 \%$ of the ELBW group compared with $16 \%$ of controls had a diagnosis of non-substance use psychiatric disorder (OR 2.5; 95\% CI 1.2, 5.1) $)^{35)}$. In another study of survivors cared for in University College London in England, $12.4 \%$ of those born $<33$ weeks' gestation compared with $4.9 \%$ of controls had been diagnosed with depression ${ }^{36)}$. Moreover, data linkage studies have identified higher rates of psychiatric problems in EP survivors compared with controls. In one data linkage study from Norway of 903,402 livebirths between 1967-1983 who were followed until 2003, schizophrenia had been diagnosed in $0.6 \%$ of those born at 23-27 weeks compared with $0.1 \%$ of those born at term, and autism spectrum had been diagnosed in $0.6 \%$ of those born at 23-27 weeks compared with $0.05 \%$ of those born at term ${ }^{37}$. In another data linkage study from Sweden, 545,628 livebirths between 1973-1979 were followed in national registers between 1987-2002. Hospital admissions with any psychiatric diagnosis between the ages of 8-29 years had occurred in 5.5\% of those born at $24-28$ weeks' gestation compared with $2.4 \%$ of those born at 39 41 weeks.

\section{QUALITY OF LIFE/FUNCTIONAL OUTCOMES}

Much data on quality of life and functional outcomes have come from Saigal et al who have followed a cohort of ELBW survivors born in a geographical region in Canada in 1977-1982 from childhood into adulthood $^{38)}$. In particular they have measured utilities on a scale from 0 (dead) to 1 (perfect health) directly from participants, firstly when they were teenagers and later when they were 23 years of age. Their general findings were that survivors born ELBW had mean utility scores of 0.85 , similar to the mean utility of 0.88 from NBW controls at 23 years of age. Moreover, there were similar proportions with utilities $>0.95$ (ELBW $62 \%$ versus controls $72 \%$ ). In both groups there had been a small decline of -0.05 in mean HRQL scores between adolescence and young adulthood.

In a subsequent publication when the cohorts were approximately 32 years of age, 100 of the ELBW group and 89 controls responded to questionnaires on various outcomes ${ }^{39)}$. The groups did not differ in the highest educational level achieved or in family and partner relationships. However, a lower proportion of ELBW adults was employed and fewer were employed full time. The mean total personal income was lower in adults born ELBW than controls, and more required social assistance. Compared with the control group, more members of the ELBW group remained single, had never had sexual intercourse, did not have children, reported more chronic health conditions, and had lower selfesteem. However, they were less likely to have drug abuse or dependence.

In the study of VLBW survivors and controls born in 1977-1979 in Cleveland, Hack et al subsequently reported that the VLBW cohort had less resilience, less risk-taking, better achievement in work performance, and similar overall health and well-being ${ }^{40)}$. In Darlow et al's study of 230 VLBW survivors born in New Zealand in 1986 and 69 controls at 22-23 years of age, there were no substantial differences in health status, self-esteem or life satisfaction between groups ${ }^{25)}$.

In a population linkage study of 570,768 livebirths born in 1973- 
1979 in Sweden, Lindstrom et al found that fewer EP survivors were married, more lived at home, and their levels of employment were similar to those born at term ${ }^{41)}$. Comparing those born EP compared with those born at term, rates of post-secondary education were lower (24-28 weeks, 26\%; 39-41 weeks, $40 \%$ ), and more received economic assistance for handicap or persistent illness (24-28 weeks, $13.2 \%$; $39-41$ weeks, $1.5 \%$ ). In a different data linkage study of 903,402 livebirths from Norway in 1967-1983, Moster et al reported similar rates of receiving a disability pension in adulthood (23-27 weeks, 10.6\%; 37+ weeks, 1.7\%) ${ }^{37)}$.

In the VICS 1991-92 cohort, self-reported measures of healthrelated quality of life, health status and self-esteem at a mean age of 18 years were similar in the ELBW/EP and control groups ${ }^{42)}$. Median utility scores were 0.93 in the ELBW/EP group and 0.95 in the controls. Median scores for self-esteem were 70 in the ELBW/ EP group compared with 60 in the control group on a scale where higher scores represent better self-esteem. The only area of health status where the ELBW/EP group scored lower than controls was for Physical Functioning, which is not surprising since more of the ELBW/EP group had motor impairments, including cerebral palsy, than did controls. ELBW/EP adolescents reported less regular physical activity over the previous six months (OR, 0.5; 95\% CI, 0.3-0.8), and lower rates of ever having sexual activity (OR, $0.6 ; 95 \%$ CI, 0.4-0.9), and of any alcohol intake over the previous month (OR, 0.5; 95\% CI, 0.3-0.8) compared with controls, but other aspects of risk-taking behaviour, such as being involved in a physical fight, cigarette smoking, smoking marijuana or being offered or having bought illicit drugs, were similar in the 2 groups.

Concerning fertility, in a population-linkage study of 1,167,506 singletons born in Norway in 1967-1988, Swamy et al reported that the relative risks (RR) for subsequent reproduction for those born at 22-27 weeks compared with those born at term were 0.24 (95\% CI $0.17,0.32)$ for males and 0.33 (95\% CI 0.26, 0.42) for females. Interestingly, women who had been born preterm, but not men born preterm, had a higher risk of having a preterm delivery themselves (22-27 weeks, $14.0 \%$; term $6.4 \%$; RR 2.4, 95\% CI 1.4, 4.2).

\section{CONCLUSIONS}

As a group, survivors born ELBW/EP face additional challenges as they reach adulthood. The higher blood pressures and metabolic aberrations observed in late adolescence or early adult- hood strongly suggest that they are destined for higher rates of cardiovascular disease in later adulthood. It appears that their airway growth is not going to achieve the peak in their early- to mid-20s that would be expected in controls, which means that more are likely to develop chronic obstructive pulmonary disease in later life. They have lower levels of cognitive performance and academic achievement, as well as difficulties with executive functioning and attention. On a positive note, although ELBW/ EP adults are shorter and lighter than controls, they achieve an adult height consistent with their genetic potential. Moreover, mental health is one area where ELBW/EP survivors are mostly no worse than controls, except for higher rates of ADHD, and some rarer, but more serious disorders, such as schizophrenia. Also, their overall levels of functioning and self-esteem are better than might have been expected given their high rates of physical and psychological problems. On the other hand, more do need assistance in daily living in the home and from the state. Adult physicians need to be aware of the higher rates of health problems of ELBW/EP survivors as more of them are now surviving into adulthood.

\section{ACKNOWLEDGMENT}

Supported by grants from the National Health and Medical Research Council of Australia (Centre of Clinical Research Excellence 546519; Centre of Research Excellence 1060733) and the Victorian government's operational infrastructure support program

\section{REFERENCES}

1) Doyle LW, Anderson PJ, Burnett AC, Callanan C, McDonald M, Hayes M, et al. Developmental disability at school age and difficulty obtaining follow-up data. Pediatrics 2017;in press Nov 2017.

2) Heron MP, Tejada-Vera B. Deaths: Leading causes for 2005. National vital statistics reports; vol 58 no 8. Hyattsville, MD: National Center for Disease Statistics 2009.

3) Cook NR, Cohen J, Hebert PR, Taylor JO, Hennekens CH. Implications of small reductions in diastolic blood pressure for primary prevention. Arch Intern Med 1995;155:701-9.

4) Hovi P, Vohr B, Ment LR, Doyle LW, McGarvey L, Morrison $\mathrm{KM}$, et al. Blood pressure in young adults born at very low birth weight: adults born preterm international collaboration. Hypertension 2016;68:880-7. 
5) Roberts G, Lee KJ, Cheong JL, Doyle LW; Victorian Infant Collaborative Study Group. Higher ambulatory blood pressure at 18 years in adolescents born less than 28 weeks' gestation in the 1990s compared with term controls. J Hypertens 2014;32: 620-6.

6) Crump C, Winkleby MA, Sundquist K, Sundquist J. Risk of hypertension among young adults who were born preterm: a Swedish national study of 636,000 births. Am J Epidemiol 2011; 173:797-803.

7) Hovi P, Andersson S, Eriksson JG, Jarvenpaa AL, StrangKarlsson S, Makitie O, et al. Glucose regulation in young adults with very low birth weight. N Engl J Med 2007;356:2053-63.

8) Sipola-Leppanen M, Vaarasmaki M, Tikanmaki M, Hovi P, Miettola S, Ruokonen A, et al. Cardiovascular risk factors in adolescents born preterm. Pediatrics 2014;134:e1072-81.

9) Stocks J, Hislop A, Sonnappa S. Early lung development: lifelong effect on respiratory health and disease. Lancet Respir Med 2013;1:728-42.

10) Doyle LW, Adams AM, Robertson C, Ranganathan S, Davis NM, Lee KJ, et al. Increasing airway obstruction from 8 to 18 years in extremely preterm/low-birthweight survivors born in the surfactant era. Thorax 2017;72:712-9.

11) Quanjer PH, Stanojevic S, Cole TJ, Baur X, Hall GL, Culver BH, et al. Multi-ethnic reference values for spirometry for the 3-95-yr age range: the global lung function 2012 equations. Eur Respir J 2012;40:1324-43.

12) Northway WH, Jr., Moss RB, Carlisle KB, Parker BR, Popp RL, Pitlick PT, et al. Late pulmonary sequelae of bronchopulmonary dysplasia. N Engl J Med 1990;323:1793-9.

13) Doyle LW, Faber B, Callanan C, Freezer N, Ford GW, Davis NM. Bronchopulmonary dysplasia in very low birth weight subjects and lung function in late adolescence. Pediatrics 2006;118:10813.

14) Gibson AM, Reddington C, McBride L, Callanan C, Robertson C, Doyle LW. Lung function in adult survivors of very low birth weight, with and without bronchopulmonary dysplasia. Pediatr Pulmonol 2015;50:987-94.

15) Saarenpaa HK, Tikanmaki M, Sipola-Leppanen M, Hovi P, Wehkalampi K, Siltanen M, et al. Lung function in very low birth weight adults. Pediatrics 2015;136:642-50.

16) Gough A, Linden M, Spence D, Patterson CC, Halliday HL, McGarvey LP. Impaired lung function and health status in adult survivors of bronchopulmonary dysplasia. Eur Respir J 2014; 43:808-16.

17) Narang I, Rosenthal M, Cremonesini D, Silverman M, Bush A. Longitudinal evaluation of airway function 21 years after preterm birth. Am J Respir Crit Care Med 2008;178:74-80.

18) Evensen KA, Steinshamn S, Tjonna AE, Stolen T, Hoydal MA, Wisloff U, et al. Effects of preterm birth and fetal growth retarda- tion on cardiovascular risk factors in young adulthood. Early Hum Dev 2009;85:239-45.

19) Vollsaeter M, Roksund OD, Eide GE, Markestad T, Halvorsen T. Lung function after preterm birth: development from midchildhood to adulthood. Thorax 2013;68:767-76.

20) Vollsaeter M, Clemm HH, Satrell E, Eide GE, Roksund OD, Markestad T, et al. Adult respiratory outcomes of extreme preterm birth. A regional cohort study. Ann Am Thorac Soc 2015; 12:313-22.

21) Vrijlandt EJ, Gerritsen J, Boezen HM, Grevink RG, Duiverman EJ. Lung function and exercise capacity in young adults born prematurely. Am J Respir Crit Care Med 2006;173:890-6.

22) Euser AM, de Wit CC, Finken MJ, Rijken M, Wit JM. Growth of preterm born children. Horm Res 2008;70:319-28.

23) Saigal S, Stoskopf B, Streiner D, Paneth N, Pinelli J, Boyle M. Growth trajectories of extremely low birth weight infants from birth to young adulthood: a longitudinal, population-based study. Pediatr Research 2006;60:751-8.

24) Roberts G, Cheong J, Opie G, Carse E, Davis N, Duff J, et al. Growth of extremely preterm survivors from birth to 18 years of age compared with term controls. Pediatrics 2013;131:e439-45.

25) Darlow BA, Horwood LJ, Pere-Bracken HM, Woodward LJ. Psychosocial outcomes of young adults born very low birth weight. Pediatrics 2013;132:e1521-8.

26) Bhutta AT, Cleeves MA, Casey PH, Cradock MM, Anand KJS. Cognitive and behavioral outcomes of school-aged children who were born preterm. A meta-analysis. JAMA 2002;288:72837.

27) Cheong JL, Anderson PJ, Roberts G, Burnett AC, Lee KJ, Thompson DK, et al. Contribution of brain size to IQ and educational underperformance in extremely preterm adolescents. PloS one 2013;8:e77475.

28) Hack M, Flannery DJ, Schluchter M, Cartar L, Borawski E, Klein N. Outcomes in young adulthood for very-low-birth-weight infants. N Engl J Med 2002;346:149-57.

29) Eide MG, Oyen N, Skjaerven R, Bjerkedal T. Associations of birth size, gestational age, and adult size with intellectual performance: evidence from a cohort of Norwegian men. Pediatr Res 2007;62:636-42.

30) Burnett AC, Scratch SE, Lee KJ, Cheong J, Searle K, Hutchinson E, et al. Executive function in adolescents born $<1000 \mathrm{~g}$ or $<28$ weeks: a prospective cohort study. Pediatrics 2015;135:e826-34.

31) Wilson-Ching M, Molloy CS, Anderson VA, Burnett A, Roberts G, Cheong JL, et al. Attention difficulties in a contemporary geographic cohort of adolescents born extremely preterm/extremely low birth weight. J Int Neuropsychol Soc 2013;19:1097108.

32) Burnett AC, Anderson PJ, Cheong J, Doyle LW, Davey CG, Wood SJ. Prevalence of psychiatric diagnoses in preterm and full- 
term children, adolescents and young adults: a meta-analysis. Psychol Med 2011;41:2463-74.

33) Burnett A, Davey CG, Wood SJ, Wilson-Ching M, Molloy C, Cheong JL, et al. Extremely preterm birth and adolescent mental health in a geographical cohort born in the 1990s. Psychol Med 2014;44:1533-44.

34) Saigal S, Stoskopf B, Boyle M, Paneth N, Pinelli J, Streiner D, et al. Comparison of current health, functional limitations, and health care use of young adults who were born with extremely low birth weight and normal birth weight. Pediatrics 2007;119: e562-73.

35) Van Lieshout RJ, Boyle MH, Saigal S, Morrison K, Schmidt LA. Mental health of extremely low birth weight survivors in their 30s. Pediatrics 2015;135:452-9.

36) Walshe M, Rifkin L, Rooney M, Healy E, Nosarti C, Wyatt J, et al. Psychiatric disorder in young adults born very preterm: role of family history. Eur Psychiatry 2008;23:527-31.

37) Moster D, Lie RT, Markestad T. Long-term medical and social consequences of preterm birth. N Engl J Med 2008;359:262-73.

38) Saigal S, Stoskopf B, Pinelli J, Streiner D, Hoult L, Paneth N, et al. Self-perceived health-related quality of life of former extremely low birth weight infants at young adulthood. Pediatrics 2006; 118:1140-8.

39) Saigal S, Day KL, Van Lieshout RJ, Schmidt LA, Morrison KM, Boyle MH. Health, wealth, social integration, and sexuality of extremely low-birth-weight prematurely born adults in the fourth decade of life. JAMA Pediatr 2016;170:678-86.

40) Hack M, Cartar L, Schluchter M, Klein N, Forrest CB. Selfperceived health, functioning and well-being of very low birth weight infants at age 20 years. J Pediatr 2007;151:635-41, e2.

41) Lindstrom K, Winbladh B, Haglund B, Hjern A. Preterm infants as young adults: a Swedish national cohort study. Pediatrics 2007;120:70-7.

42) Roberts G, Burnett AC, Lee KJ, Cheong J, Wood SJ, Anderson PJ, et al. Quality of life at age 18 years after extremely preterm birth in the post-surfactant era. J Pediatr 2013;163:1008-13. 